\title{
El projecte «terradebruixes» i els processos per bruixeria andorrans: entre la recerca històrica i la divulgació
}

\section{Between historical research and divulgation: 'The «terradebruixes» project and the andorran witchcraft processes}

\author{
Pau Castell Granados \\ paucastell@ub.edu
}

Universitat de Barcelona

\begin{abstract}
Resum: Les investigacions dutes a terme durant les últimes dècades han posat en relleu la singularitat i la rellevància de la documentació andorrana relativa al fenomen històric conegut com a «cacera de bruixes», tot destacant l'elevat nombre de processos per bruixeria conservats per als segles XV-XVII. Aquesta realitat documental ha motivat un projecte de recerca finançat pel Govern d'Andorra i basat en la recopilació i estudi del total de processos per bruixeria conservats al fons «Tribunal de Corts» de l'Arxiu Nacional d'Andorra. Els resultats d'aquest projecte han estat recollits en un espai web articulat al voltant d'un atles interactiu de les valls i d'una base de dades formada per desenes de fitxes individuals dotades d'un sistema d'etiquetes i enllaços, fet que converteix aquesta plataforma en una potent eina de recerca per als especialistes i, alhora, en una experiència innovadora de cara a la difusió i posada en valor de la recerca entre el gran públic.
\end{abstract}

Paraules clau: processos, bruixeria, Andorra, Humanitats Digitals

\begin{abstract}
The research carried out during the last decades has pointed up the relevance and uniqueness of the Andorran sources concerning the historical phenomenon of witch-hunts, by highlighting the large number of witchcraft trials preserved for the 15th-17th centuries. This archival reality has motivated the development of a research project financed by the Andorran Government and devoted to the collection and study of the totallity of witchcraft trials preserved in the series «Tribunal de Corts» of the Arxiu Nacional d'Andorra. The project's results have been displayed in a web page containing an interactive atlas and a database composed of dozens of individual files enriched with a system of tags and hyperlinks. The platform therefore becomes a powerful tool for researchers as well as an innovative experience regarding the dissemination and valorisation of research among the general public.
\end{abstract}

Keywords: trials, witchcraft, Andorra, Digital Humanities

\footnotetext{
* El present treball ha estat finançat pel Govern d'Andorra a través de l'Ajut d'investigació històrica «Cebrià Baraut» corresponent a la convocatòria 2015-2017 (ref. 0069-48220).
}

DATA PRESENTACIÓ: 13/04/2019 ACCEPTACIÓ: 20/05/2019 • PUBLICACIÓ: 23/06/2019 
Pau Castell Granados. El projecte «terradebruixes» i els processos per bruixeria andorrans: entre

la recerca històrica i la divulgació

\section{Preliminar}

A final del segle XIX, l'arxiver i historiador francès Jean-Auguste Brutails (1859-1926) fou nomenat jutge del Tribunal superior d'Andorra, càrrec que exercí durant gairebé quatre dècades, al llarg de les quals publicà diversos estudis sobre la història, les costums i l'evolució del dret andorrà en època medieval i moderna. L'any 1904, en una de les seves obres titulada «La coutume d'Andorre», Brutails reconeixia que allò que més l'havia frapat de l'antiga criminalitat andorrana era l'abundància de processos per bruixeria (Brutails 1904: 12) ${ }^{1}$. L'observació d'aquell erudit evidenciava una realitat documental excepcional i sovint ignorada per bona part de la historiografia posterior. A dia d'avui, els fons de l'anomenat Tribunal de Corts, custodiats a l'Arxiu Nacional d'Andorra (ANA), se situen efectivament entre els més fecunds del continent pel que fa a aquest tipus de documentació, fet que converteix el Principat en un espai privilegiat per a l'estudi del fenomen històric conegut com a «cacera de bruixes».

Des del temps de Jean-Auguste Brutails, els investigadors han trobat en els arxius andorrans una via per aproximar-se a aquest episodi inquietant de la història d'Europa, a través del testimoni que ens ofereixen els nombrosos judicis per bruixeria celebrats al llarg dels segles XV-XVII per part d'unes corts de justícia sovint allunyades de l'ordre del dret i disposades a prescindir de les mínimes garanties legals i processals per tal d'obtenir sentències de culpabilitat. Uns judicis que s'alimentaren de la sospita $i$ el rumor veïnals per actuar contra una sèrie de dones, acusant-les de provocar la malaltia i la mort a través de maleficis i metzines, de desencadenar pedregades destructores, de reunir-se en aplecs diabòlics per abjurar de la fe cristiana i, en definitiva, de formar part de la temible secta d'adoradors del «boc de Biterna».

Malgrat la riquesa dels arxius andorrans, caldria esperar gairebé un segle per trobar noves aportacions sobre aquest fenomen per part de la historiografia especialitzada. L'any 1990, l'investigador JeanFrançois Galinier-Pallerola publicava la seva tesi doctoral, defensada a la Universitat de Tolosa i dedicada a la religiositat andorrana, en la qual incloïa una primera aproximació al tema de la bruixeria a partir de la documentació de l'ANA (Galinier-Pallerola 1990: 129-164). El total de disset processos analitzats per Galinier-Pallerola, foren ampliats considerablement l'any 2004 mercès al treball de Robert Pastor -el primer dedicat de manera monogràfica al fenomen de la bruixeria andorrana-, i gràcies també a l'obra de l'historiador danès Lars Martin Pohle, publicada al 2008 i centrada en els episodis repressius del segle XVII (Pastor 2004; Pohle 2008). Ambdues obres es beneficiaren dels incipients treballs de catalogació endegats per l'Arxiu Nacional en l'esmentat fons del Tribunal de Corts i en el de l'Arxiu de les Set Claus, coordinats per l'arxivera i historiadora andorrana Susanna Vela. Un cop finalitzats els treballs de catalogació, els fons del Tribunal de Corts foren abordats de nou durant la nostra tesi doctoral dedicada a la cacera de bruixes a Catalunya, presentada a la

1 «Ce qui m’a le plus frappé dans l'ancienne criminalité andorrane, c'est la fréquence des procès de sorcellerie...» (Brutails 1904: 12).

SCRIPTA, Revista internacional de literatura i cultura medieval i moderna, núm. 13 / juny 2019 / pp. 243 - 256 ISSN: 2340-4841 · doi:10.7203/SCRIPTA.13.15483 
Pau Castell Granados. El projecte «terradebruixes» i els processos per bruixeria andorrans: entre la recerca històrica i la divulgació

Universitat de Barcelona l'any 2013 i centrada en els episodis repressius dels segles XV i XVI. La recerca efectuada ens va permetre elevar novament el nombre de processos identificats, els quals foren també objecte d'una primera transcripció i edició paleogràfica, així com d'un estudi comparatiu amb els judicis coetanis celebrats en altres regions europees (Castell 2013) ${ }^{2}$.

En conjunt, els treballs esmentats contribuïren a donar a conèixer la singularitat i la rellevància de la documentació andorrana relativa a la persecució de la bruixeria, caracteritzada per l'elevat nombre de judicis conservats per als segles XV-XVII. Uns segles durant els quals el Principat esdevingué un dels epicentres de la cacera de bruixes a Europa, amb un Tribunal de Corts decidit a «purgar les valls» d'aquelles dones malèfiques per mitjà de la forca i la foguera.

És precisament aquesta realitat històrica i documental la que ens ha portat a impulsar un projecte de recerca, finançat pel Govern d'Andorra a través de l'Ajut Cebrià Baraut, sota el títol «Per purgar les valls de tan pèssimes dones. Projecte de recerca històrica i divulgació multimèdia sobre la cacera de bruixes a Andorra» (2015-2018). L'esmentat projecte ha tingut com a primer objectiu completar el buidatge documental dels arxius andorrans per tal d'identificar i recopilar la totalitat de processos judicials i d'accions contra la bruixeria desenvolupats al Principat durant el període 1400-1700. Així mateix, s'ha procedit a l'anàlisi de la documentació històrica recollida per tal d'obtenir una visió de conjunt sobre la cacera de bruixes andorrana, tot identificant-ne la mecànica, els condicionants i l'evolució al llarg dels gairebé tres-cents anys de persecució anti-bruixesca. El treball amb les fonts ha permès també complementar aquesta imatge de conjunt amb una visió de detall, basada en la identificació del total de persones assenyalades, processades i condemnades per bruixeria a les valls durant els segles de la cacera, així com de les relacions familiars i veïnals de les mateixes. Finalment, un dels elements destacats del projecte ha consistit en la creació d'un espai web articulat al voltant d'un atles interactiu de les Valls i d'una base de dades relacional, per tal d'organitzar, presentar i difondre adequadament els resultats de la investigació.

Aquesta plataforma web, accessible en línia des del passat mes de març de 2019 [http:// terradebruixes.cultura.ad], constitueix una potent eina de recerca històrica i documental al servei dels especialistes $i$ alhora una finestra oberta al gran públic. Així mateix, el procés de recerca arxivística, anàlisi, disseny i implementació de l'atles interactiu i de la base de dades relacional ha resultat una experiència innovadora i altament enriquidora que ens permet evidenciar un cop més la potencialitat de les anomenades Humanitats Digitals pel que fa a la recerca, la posada en valor i la divulgació del patrimoni històric i documental.

2 Aquest treball fou guardonat amb el premi extraordinari de Doctorat, el premi Joan Reglà de l'Institut d'Estudis Catalans, el premi de la Fundació Noguera i l'accèssit al premi del Claustre de Doctors de la Universitat de Barcelona. En breu en serà publicada una versió revisada i ampliada per part de la Fundació Noguera.

SCRIPTA, Revista internacional de literatura i cultura medieval i moderna, núm. 13 / juny 2019 / pp. 243 - 256 ISSN: 2340-4841 · doi:10.7203/SCRIPTA.13.15483 
Pau Castell Granados. El projecte «terradebruixes» i els processos per bruixeria andorrans: entre la recerca històrica i la divulgació

\section{Les xifres de la cacera andorrana}

Els treballs realitzats al llarg del projecte han portat a la identificació d'una seixantena de processos per bruixeria conservats al fons del Tribunal de Corts de l'Arxiu Nacional d'Andorra (fig. 1), complementats amb altra documentació de tipus legal o comptable conservada en el fons de l'Arxiu de les Set Claus (fig. 2). Pel que fa als processos de corts, alguns es conserven en la seva totalitat, des de l'enquesta de testimonis i la detenció de les sospitoses fins a la sentència final, passant pels primers interrogatoris, els peritatges, els articles de descàrrec, les eventuals sentències interlocutòries, les sessions de turment, els informes pericials i, en ocasions, els informes d'assessors $\mathrm{i}$ juristes abans de procedir a la sentència definitiva. Tanmateix, bona part dels processos s'han conservat de manera fragmentària. En alguns casos disposem únicament de l'enquesta de testimonis i el primer interrogatori de la sospitosa, mentre que en ocasions es conserva extrapolada la confessió de les acusades o la sentència final. En un parell de casos s'ha conservat també l'inventari dels béns de la condemnada o les deixes testamentàries, així com les despeses efectuades el dia de l'execució.

\begin{tabular}{|l|l|l|}
\hline Any & Contingut & Ref. arxivística \\
\hline c.1420-1430 & Fragment de sentència contra Caterina Yvona d'Escaldes & ANA, TC, doc.5161 \\
\hline 1460 & Procés contra Maria Carta d'Andorra la Vella & ANA, TC, doc.1799 \\
\hline 1471 & Procés contra Esclarmonda Aymar d'Engordany & ANA, TC, doc.1804 \\
\hline 1471 & Procés contra Margarida Anglada «Guillema» d'Encamp & ANA, TC, doc.1806 \\
\hline 1471 & Procés contra Guillema Casala de Canillo & ANA, TC, doc.5947 \\
\hline 1471 & Procés contra Joana Call «Sucarranya» d'Engordany & ANA, TC, doc.5948 \\
\hline c.1471 & Procés contra Maria Guida «Tomassa» d'Encamp & ANA, TC, doc.5090 \\
\hline 1472 & Procés contra Joana Call de Segudet & ANA, TC, doc.1760 \\
\hline c.1472 & Procés contra Maria Busqueta «Escaça» d'Escàs & ANA, TC, doc.2018 \\
\hline 1473 & Procés contra Caterina Tarrada d'Engordany & ANA, TC, docs.1759, \\
\hline 1489 & Procés contra Margarida Duranda de Canillo & 1798 i 5951 \\
\hline 1499 & Procés contra Dolça Narbona de Vila & ANA, TC, doc.1832 \\
\hline 1499 & Procés contra Maria Tomassa d'Encamp & $\begin{array}{l}\text { ANA, TC, docs.1874 i } \\
\text { 1881 }\end{array}$ \\
\hline $1514 / 1515 / 1522$ & Procés contra Maria Martina d'El Tarter & ANA, TC, doc.5973 \\
\hline 1516 & Procés contra Marta Guisalda d'Aixirivall & ANA, TC, doc.6014 \\
\hline c.1516 & Fragment de l'enquesta contra Caterina Fontana d'El Vilar & ANA, TC, doc.1890 \\
\hline 1529 & Procés contra Francina Quera d'Engordany & ANA, TC, doc.2204 \\
\hline 1532 & Fragment de l'enquesta contra Maria Call de Llorts & ANA, TC, doc.2218 \\
\hline
\end{tabular}


Pau Castell Granados. El projecte «terradebruixes» i els processos per bruixeria andorrans: entre la recerca històrica i la divulgació

\begin{tabular}{|c|c|c|}
\hline 1533 & Fragment de l'enquesta contra Martineta Pellissera d'Encamp & ANA, TC, doc. 2223 \\
\hline 1545 & Procés contra Margarida Guisalda d'Aixirivall & $\begin{array}{l}\text { ANA, TC, docs.2342 i } \\
6041\end{array}$ \\
\hline 1546 & Fragment de la confessió de Joana Mora de Canillo & ANA, TC, doc. 2348 \\
\hline c.1546 & $\begin{array}{l}\text { Fragment de l'enquesta contra na Quera «Andreu-Dòria» } \\
\text { d'Engordany }\end{array}$ & ANA, TC, doc.1989 \\
\hline 1551 & Enquestes de testimonis a Canillo i Encamp & ANA, TC, doc.6053 \\
\hline 1551 & Procés contra Jalmina Cella de Llorts & ANA, TC, doc. 2417 \\
\hline $1551 / 1554$ & Procés contra Antònia Martina d'El Tarter & ANA, TC, doc.6052 \\
\hline 1574 & Procés contra Antònia Joanica de Sant Julià de Lòria & ANA, TC, doc. 2730 \\
\hline 1574 & Confessió de Margarida Sabatera de Mosquera & ANA, TC, doc. 2741 \\
\hline 1576 & Fragment de l'enquesta contra Caterina Tomassa de Les Bons & ANA, TC, doc. 2750 \\
\hline 1593 & Procés contra Francesca Cantúrria d’Àreu (Vallferrera) & ANA, TC, doc.6154 \\
\hline 1593 & Procés contra Joana Rossella de Surnàs & ANA, TC, doc.2871 \\
\hline $1593 / 1604 / 1606$ & Procés contra Jaumina Armengoua «Salvatja» d’Encamp & $\begin{array}{l}\text { ANA, TC, docs.2875 i } \\
3064\end{array}$ \\
\hline $1593 / 1604$ & Procés contra Maria Jaume-Joana «Sastressa» de Llorts & $\begin{array}{l}\text { ANA, TC, docs.2871, } \\
3061,3066,3067 \text { i } 6194\end{array}$ \\
\hline 1593 & Interrogatori de Joana Tomassa d'El Tarter & ANA, TC, doc. 2877 \\
\hline 1604 & Enquesta de testimonis contra Maria Riba Jussana de Sispony & ANA, TC, doc.3068 \\
\hline $1604 / 1608$ & Procés contra Peyrona Gastona de Canillo & ANA, TC, doc.3069 \\
\hline 1604 & Enquesta de testimonis a Canillo & ANA, TC, doc.3071 \\
\hline $1604 / 1621$ & Procés contra Caterina Foresta de Canillo & ANA, TC, doc.6193 \\
\hline $1604 / 1621$ & Procés contra Paula Garreta «Arnau-Martina» de Mosquera & $\begin{array}{l}\text { ANA, TC, docs.3192, } \\
6234 \text { i } 6235\end{array}$ \\
\hline 1621 & Procés contra Àngela Borrellona de La Massana & ANA, TC, doc. 6237 \\
\hline 1621 & Procés contra Maria Galoxa d’El Vilaró & ANA, TC, doc.6238 \\
\hline 1621 & Procés contra Joana Martí i Tor de La Cortinada & ANA, TC, doc.6239 \\
\hline 1621 & Procés contra Maria Call de Segudet & ANA, TC, doc. 6240 \\
\hline 1621 & Procés contra Esclusa la vella de Pal & ANA, TC, doc. 6241 \\
\hline 1621 & Procés contra Jaumina Fustera de Sant Julià de Lòria & ANA, TC, doc. 6242 \\
\hline 1621 & $\begin{array}{l}\text { Procés contra Joana Naudina «Busqueta» de Sant Julià de } \\
\text { Lòria }\end{array}$ & ANA, TC, doc. 6243 \\
\hline 1621 & Procés contra Maria Sucarrana de La Cortinada & ANA, TC, doc. 6244 \\
\hline 1621 & Procés contra Isabel Rufona de La Cortinada & ANA, TC, doc. 6245 \\
\hline 1621 & Procés contra Antònia Naudina «Som» de Canillo & ANA, TC, doc. 6246 \\
\hline 1621 & Procés contra Margarida Rusca de Soldeu & ANA, TC, doc. 6247 \\
\hline $1621 / 1629$ & Procés contra Miquela Llumeneres de Sant Julià de Lòria & ANA, TC, doc. 6248 \\
\hline 1621 & Procés contra Joana Tora de Bixessarri & ANA, TC, doc.6249 \\
\hline 1621 & $\begin{array}{l}\text { Procés contra Margarida Foixenca «la Bearnesa» d'Andorra } \\
\text { la Vella }\end{array}$ & ANA, TC, doc. 6253 \\
\hline
\end{tabular}


Pau Castell Granados. El projecte «terradebruixes» i els processos per bruixeria andorrans: entre la recerca històrica i la divulgació

\begin{tabular}{|l|l|l|}
\hline 1621 & Procés contra Caterina Fijada d'Ansalonga & ANA, TC, doc.6254 \\
\hline 1621 & Procés contra Maria Sinyer d'El Puiol del Pui & ANA, TC, doc.3198 \\
\hline $1621 / 1629$ & Procés contra Antònia Riba «Corneta» de Sispony & ANA, TC, doc.3199 \\
\hline $1621 / 1629$ & Procés contra Maria Naudina de Pere Pont de Canillo & ANA, TC, doc.3201 \\
\hline $1629-30$ & Procés de Joana dels Torns i Call d'Andorra la Vella & ANA, TC, doc.6276 \\
\hline $1632 / 1642$ & Enquesta contra Maciana Ricarda d'Engordany & ANA, TC, doc.6284 \\
\hline 1643 & Enquesta contra Peronella Garrona «Moroges» de Canillo & ANA, TC, doc.6333 \\
\hline 1643 & Enquesta contra Joana Pasquala de La Massana & ANA, TC, doc.3291 \\
\hline
\end{tabular}

Fig.1 Processos per bruixeria conservats al fons Tribunal de Corts (elaboració pròpia)

Pel que fa a les referències legals o comptables procedents de l'Arxiu de les Set Claus, algunes corresponen efectivament a judicis conservats, mentre d'altres consignen actuacions judicials o confiscacions de béns de dones condemnades per bruixeria de les quals no se'n conserva el procés.

En aquest sentit, l'estudi detallat de la documentació ens ha permès identificar un gran nombre de dones acusades o processades per bruixeria en judicis coetanis, dels quals en tenim referències indirectes a través dels esments comptables, les deposicions testimonials o les confessions de les pròpies delades. En ocasions disposem també del nom de les suposades còmplices identificades per les delades durant els habituals interrogatoris «in caput sociorum», els quals acostumaven a facilitar l'obertura de noves accions judicials, sovint perdudes o només parcialment conservades.

\begin{tabular}{|l|l|l|}
\hline Any & Contingut & Ref. arxivística \\
\hline 1545 & $\begin{array}{l}\text { Carta del bisbe Urries als cònsols i prohoms d'Andorra sobre els judicis } \\
\text { per bruixeria endegats pel Tribunal de Corts }\end{array}$ & ANA, ASC, doc.693 \\
\hline 1551 & $\begin{array}{l}\text { Crida pública dels veguers de les Valls per iniciar les actuacions contra } \\
\text { la bruixeria }\end{array}$ & ANA, ASC, doc.31 \\
\hline 1551 & $\begin{array}{l}\text { Súplica dels prohoms d'Andorra als veguers per aturar les confiscacions } \\
\text { de béns a les condemnades per bruixeria }\end{array}$ & $\begin{array}{l}\text { ANA, ASC, Llibre 36, } \\
\text { f.149v-153r }\end{array}$ \\
\hline 1551 & $\begin{array}{l}\text { Informe del jurista Pere Abella sobre les condemnes per bruixeria } \\
\text { dictades pel Tribunal de Corts }\end{array}$ & ANA, ASC, doc.695 \\
\hline 1621 & $\begin{array}{l}\text { Concòrdia del Consell de la Terra sobre la manera de procedir contra la } \\
\text { bruixeria }\end{array}$ & ANA, ASC, doc.206 \\
\hline
\end{tabular}


Pau Castell Granados. El projecte «terradebruixes» i els processos per bruixeria andorrans: entre la recerca històrica i la divulgació

\begin{tabular}{|l|l|l|}
\hline 1621 & Actes del Consell de la Terra relatives a l'execució de bruixes & $\begin{array}{l}\text { ANA, ASC, Llibre 2, } \\
\text { f.16r-18v }\end{array}$ \\
\hline $\begin{array}{l}1621- \\
1626\end{array}$ & $\begin{array}{l}\text { Aixecament de les corts i memorial comptable dels deutes de les dones } \\
\text { condemnades per bruixeria }\end{array}$ & $\begin{array}{l}\text { ANA, ASC, Llibre 2, } \\
\text { f.93r-96r }\end{array}$ \\
\hline 1629 & $\begin{array}{l}\text { Disposicions del Consell de la Terra relatives a la confiscació dels béns } \\
\text { de les dones condemnades per bruixeria }\end{array}$ & ANA, ASC, doc.751 \\
\hline 1629 & Actes del Consell de la Terra relatives a l'execució de bruixes & $\begin{array}{l}\text { ANA, ASC, Llibre 2, } \\
\text { f.125v-129v }\end{array}$ \\
\hline $\begin{array}{l}1629- \\
1639\end{array}$ & $\begin{array}{l}\text { Anotacions comptables fetes pel Consell de la Terra relatives a l'execució } \\
\text { de bruixes i els consegüents pagaments a la cort i al Consell }\end{array}$ & $\begin{array}{l}\text { ANA, ASC, Llibre 2, } \\
\text { f.89v-92vi 158r }\end{array}$ \\
\hline
\end{tabular}

Fig. 2 Documentació relativa a la bruixeria conservada a l'Arxiu de les Set Claus (elaboració pròpia)

Un cop finalitzat l'anàlisi del conjunt de documentació conservada, hem pogut identificar un total de 160 persones (majoritàriament dones) assenyalades, acusades, processades i/o condemnades per bruixeria pel Tribunal de Corts andorrà al llarg dels segles XV-XVII.

Pel que fa a aquest interessant volum documental, cal remarcar que no es tracta en cap cas de documentació seriada, sinó de peces diverses i sovint fragmentàries que han sobreviscut entre els fons de l'antic arxiu del Tribunal de Corts. Aquest fet desaconsella una confiança excessiva en anàlisis de tipus estadístic o merament quantitatiu, conscients que disposem únicament d'una part per bé que significativa- del total d'accions judicials contra la bruixeria endegades per les autoritats andorranes durant els segles de la cacera. Tanmateix, la documentació treballada ens permet ja apuntar algunes tendències i evidenciar les diverses fases de la persecució al Principat al llarg dels segles XV-XVII (fig. 3).

Així, després d'una sèrie de referències indirectes a judicis celebrats durant les dècades centrals del segle XV, documentem una primera gran actuació contra la bruixeria durant els anys 14711473 , amb una vintena de dones processades, seguida d'un segon grup de judicis per bruixeria endegats durant les corts de 1499. Les característiques d'aquelles primeres actuacions marquen la pauta seguida pel tribunal andorrà al llarg dels segles següents, amb un clar predomini del sexe femení entre les acusades, un paper central de la fama i el rumor com a vehiculador de les acusacions veïnals, una subversió evident de l'ordre del dret i un abús del turment judicial per obtenir confessions inculpatòries, un predomini de l'infanticidi i l'emmetzinament entre els càrrecs imputats, $\mathrm{i}$ una coherència del constructe demonològic relatiu a l'aplec diabòlic $\mathrm{o}$ sabbat. 
Pau Castell Granados. El projecte «terradebruixes» i els processos per bruixeria andorrans: entre la recerca històrica i la divulgació

Un cop entrats al segle XVI, s'inicia un període d'actuacions recurrents a partir de les corts de 1514 que es clou amb l'intens episodi repressiu de 1551, deixant un balanç d'una cinquantena de dones acusades o condemnades per bruixes i metzineres. Al llarg d'aquestes dècades detectem també els primers intents per frenar o matisar les actuacions judicials contra la bruixeria al Principat, tal com evidencien la carta del bisbe Urries de 1545, els informes demanats a l'escèptic jurista Pere Abella al 1551 o la súplica dels prohoms de les valls dirigida al veguer francès per posar fi a les letals confiscacions de béns de les condemnades. Amb posterioritat a l'episodi de 1551, la segona meitat del segle XVI es caracteritzà per una clara davallada dels processos per bruixeria, coincidint també amb els anys de major intervenció inquisitorial a les valls. En aquest sentit, conservem el rastre d'una única actuació endegada pel Tribunal de Corts l'any 1574, la qual es veuria frenada pel Sant Ofici de Barcelona (Castell 2017: 74-76).



Fig. 3 Evolució de la persecució contra la bruixeria a Andorra (elaboració pròpia)

Després d'unes dècades de baixa intensitat persecutòria, l'hivern de 1593 s'inicià una nova actuació contra la bruixeria per part del Tribunal de Corts, amb una vintena d'encausades. Sembla que en aquella ocasió la majoria de dones acabaren essent alliberades sota fiança, si bé algunes d'elles serien novament detingudes i finalment condemnades a penes d'assots, desterro o mort a la forca durant els primers anys del segle XVII. Aquelles condemnes foren el presagi funest de la gran persecució que havia d'arribar pocs anys després, a principis de la dècada de 1620, coincidint amb les grans caceres que s'estengueren arreu de Catalunya. 
Pau Castell Granados. El projecte «terradebruixes» i els processos per bruixeria andorrans: entre la recerca històrica i la divulgació

Cal recordar que el període 1614-1622 va marcar el punt àlgid de la cacera de bruixes al Principat català, amb centenars de dones processades en les viles i ciutats de la plana i en les diverses senyories pirinenques, coincidint amb una sèrie de desastres climàtics $i$ epidèmics que feren multiplicar les acusacions populars per bruixeria (Alcoberro 2008 i 2012; Castell 2017 i 2018). En aquell context, les valls d'Andorra van viure també el seu particular episodi repressiu de grans dimensions, el qual s'inicià l'estiu de 1621 i acabà comportant el processament d'una trentena llarga de dones en l'espai de pocs mesos. Aquell episodi s'inicià amb una concòrdia signada entre els veguers i el Consell de la Terra, seguida de l'obertura d'accions judicials que quedaren també registrades en els llibres comptables del Consell, el qual es feu càrrec del cobrament de les multes de 25 lliures imposades a les condemnades. Aquell episodi, que marca el zenit de la persecució andorrana, tindria un segon rebrot l'any 1629 coincidint amb l'extensió d'una mortífera epidèmia a les valls. En aquella ocasió, una dotzena de dones foren detingudes i condemnades, amb les consegüents confiscacions de béns per sufragar el pagament de les 25 lliures estipulat en la concòrdia de 1621. Amb posterioritat a l'intens episodi repressiu de 1621-1629, la cacera de bruixes aniria perdent intensitat a les Valls d'Andorra -de manera similar al cas català- fins a desaparèixer definitivament a finals d'aquella centúria. Durant aquells anys, les corts recolliren testimonis en alguna ocasió contra dones assenyalades com a bruixes pels seus veïns i veïnes, però ja no es tornà a dictar cap sentència de mort per bruixeria a les Valls d'Andorra.

\section{La base de dades i l'atles interactiu}

Els resultats de la investigació efectuada durant el projecte es troben actualment recollits en l'esmentada plataforma web, articulada al voltant d'un atles interactiu de les valls d'Andorra i d'una base de dades on es consignen el total de dones acusades, els personatges i els esdeveniments més destacats de la cacera andorrana.

La navegació a través de l'atles es realitza per mitjà d'una barra temporal on es consignen els esmentats períodes i episodis repressius, cadascun dels quals conté la informació geolocalitzada sobre les dones assenyalades o condemnades en aquella ocasió i els personatges o esdeveniments més destacats relacionats amb la persecució (fig. 4). Els vuit mapes resultants van acompanyats de la descripció de l'episodi en qüestió, seguit dels noms de les acusades. Clicant sobre qualsevol d'aquestes persones es desplega la informació sobre el seu lloc d'origen, la data en què foren processades i una descripció sumària del cas, tot plegat acompanyat de les corresponents referències arxivístiques $i$ de breus extrets documentals. En alguns casos s'han indicat també els llocs de celebració de l'aplec diabòlic tal com apareixen consignats en les confessions de les delades. En els períodes amb un 
Pau Castell Granados. El projecte «terradebruixes» i els processos per bruixeria andorrans: entre

la recerca històrica i la divulgació

major nombre d'actuacions judicials, s'ha incorporat també una llegenda amb diversos tons cromàtics per indicar els anys de celebració de les corts.

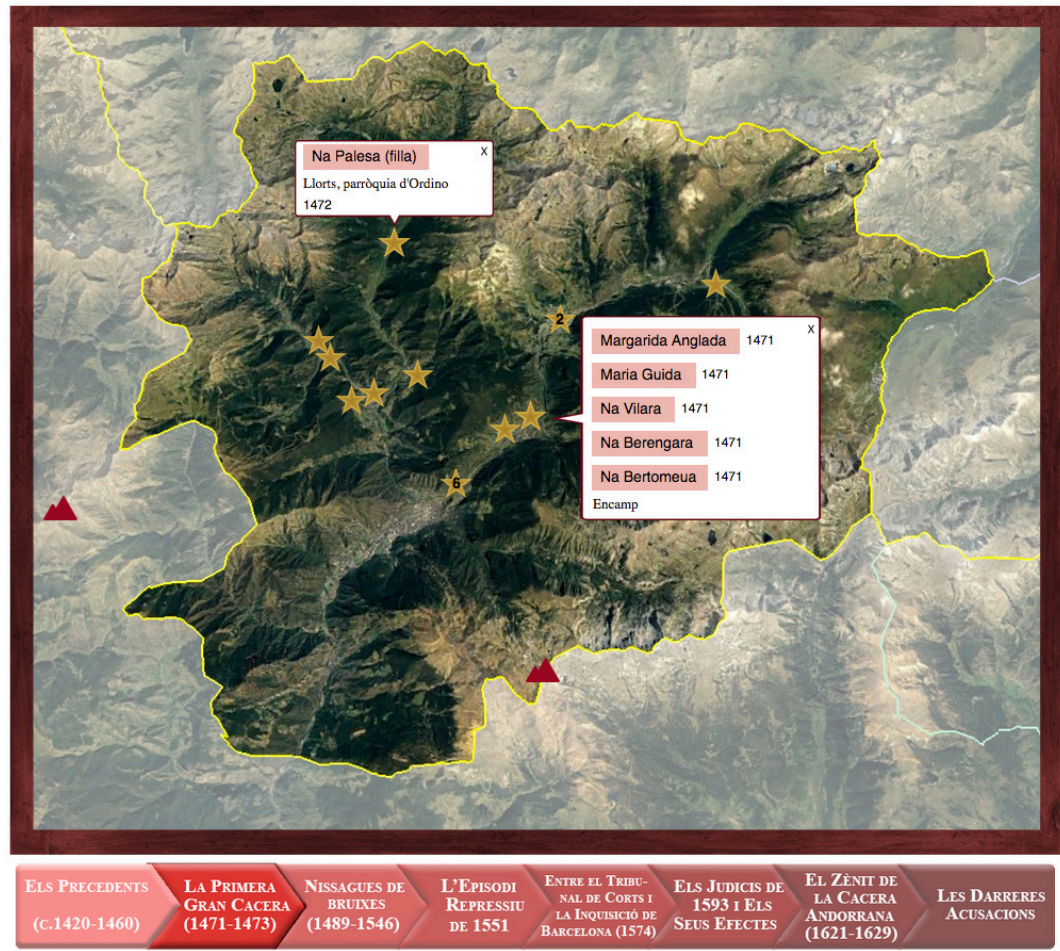

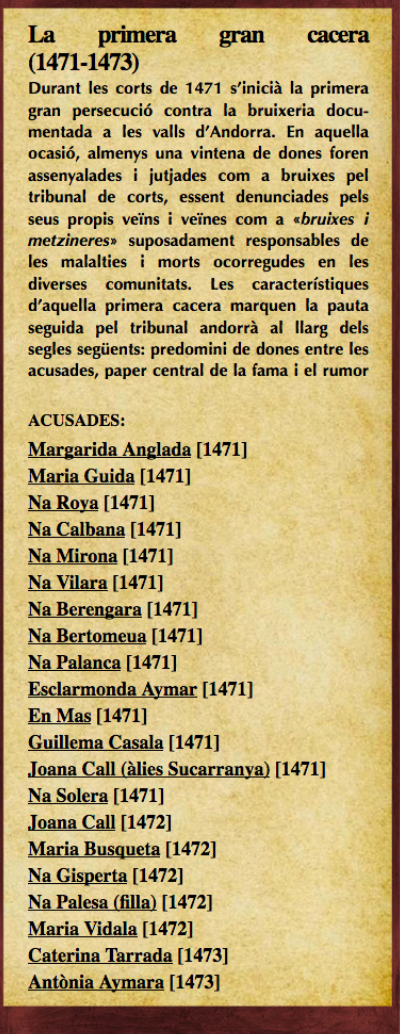

Fig. 4 Captura de pantalla de l'atles interactiu http://terradebruixes.cultura.ad/index.php/atles

A banda de l'atles, la web disposa també d'una base de dades interactiva on apareixen recollides les fitxes individuals relatives a les persones acusades, els personatges i esdeveniments destacats $i$ els llocs de celebració de l'aplec diabòlic. Les fitxes que conformen aquesta base de dades estan relacionades entre si amb un sistema d'enllaços $i$ han estat enriquides amb una sèrie d'etiquetes per facilitar cerques sobre aspectes concrets. 
Pau Castell Granados. El projecte «terradebruixes» i els processos per bruixeria andorrans: entre la recerca històrica i la divulgació

Pel que fa als enllaços, aquests permeten aprofundir en alguns aspectes interessants per a la recerca com ara les relacions familiars de les acusades o l'entramat d'acusacions i delacions que s'anava teixint al llarg dels processos. En aquest sentit, una de les característiques de la cacera andorrana fou la transmissió de la fama de bruixa a les descendents de les acusades, fet que sovint comportava l'acumulació d'acusacions per bruixeria contra membres d'una mateixa casa o família al llarg de generacions. La navegació a través d'aquestes fitxes individuals permet així localitzar i accedir a través dels enllaços a les fitxes de les antecessores o les descendents de l'acusada, fet que evidencia l'existència d'autèntiques «nissagues de bruixes» en moltes poblacions andorranes. Per altra banda, la pràctica habitual de la delació de còmplices durant les confessions sota turment fou un element determinant en moltes de les actuacions contra la bruixeria endegades pel Tribunal de Corts. El sistema d'enllaços permet resseguir l'evolució d'aquestes actuacions judicials: a partir d'un primer procés en el que l'acusada identificava eventualment una sèrie de dones com a còmplices, es procedia a la seva detenció i a la consegüent fortificació de les enquestes, en un autèntic «efecte dòmino» de conseqüències realment funestes.

Pel que fa al sistema d'etiquetatge, s'ha optat per enriquir cada fitxa amb una sèrie d'etiquetes relatives a aspectes diversos com ara el lloc d'origen de les acusades; els càrrecs imputats (\#infanticidi, \#metzines, \#pedregada); la utilització de la tortura (\#turment); el desenllaç dels judicis (\#pena de mort, \#absolució, \#llibertat sota fiança, \#desterro, \#fugida); el mètode d'execució (\#forca, \#foguera, \#esquarterament); la presència d'elements demonològics (\#aplec diabòlic, \#boc de Biterna); la presència d'homes entre els acusats (\#bruixot) o la intervenció del Sant Ofici (\#Inquisició), entre altres. Aquestes etiquetes apareixen al final de cada fitxa individual i es troben també agrupades en un núvol sempre visible en pantalla, on el diferent mòdul de la lletra indica aquelles etiquetes amb un major o menor nombre de casos registrats (fig.5). Així, el núvol permet identificar ràpidament aspectes remarcables, com ara les localitats amb un major nombre de persones acusades (i.e. Canillo, Encamp i Engordany), els càrrecs i sentències més habituals (infanticidi, pena de mort) o l'elevat nombre de vídues entre les dones acusades (\#vídua).

Finalment, la plataforma permet, igualment, efectuar cerques amb text lliure, oferint així la possibilitat a l'usuari de navegar pel contingut de la base de dades a la recerca d'aquells elements que consideri interessants i que no apareguin recollits en el sistema d'etiquetatge que hem porposat. 
Pau Castell Granados. El projecte «terradebruixes» i els processos per bruixeria andorrans: entre la recerca històrica i la divulgació

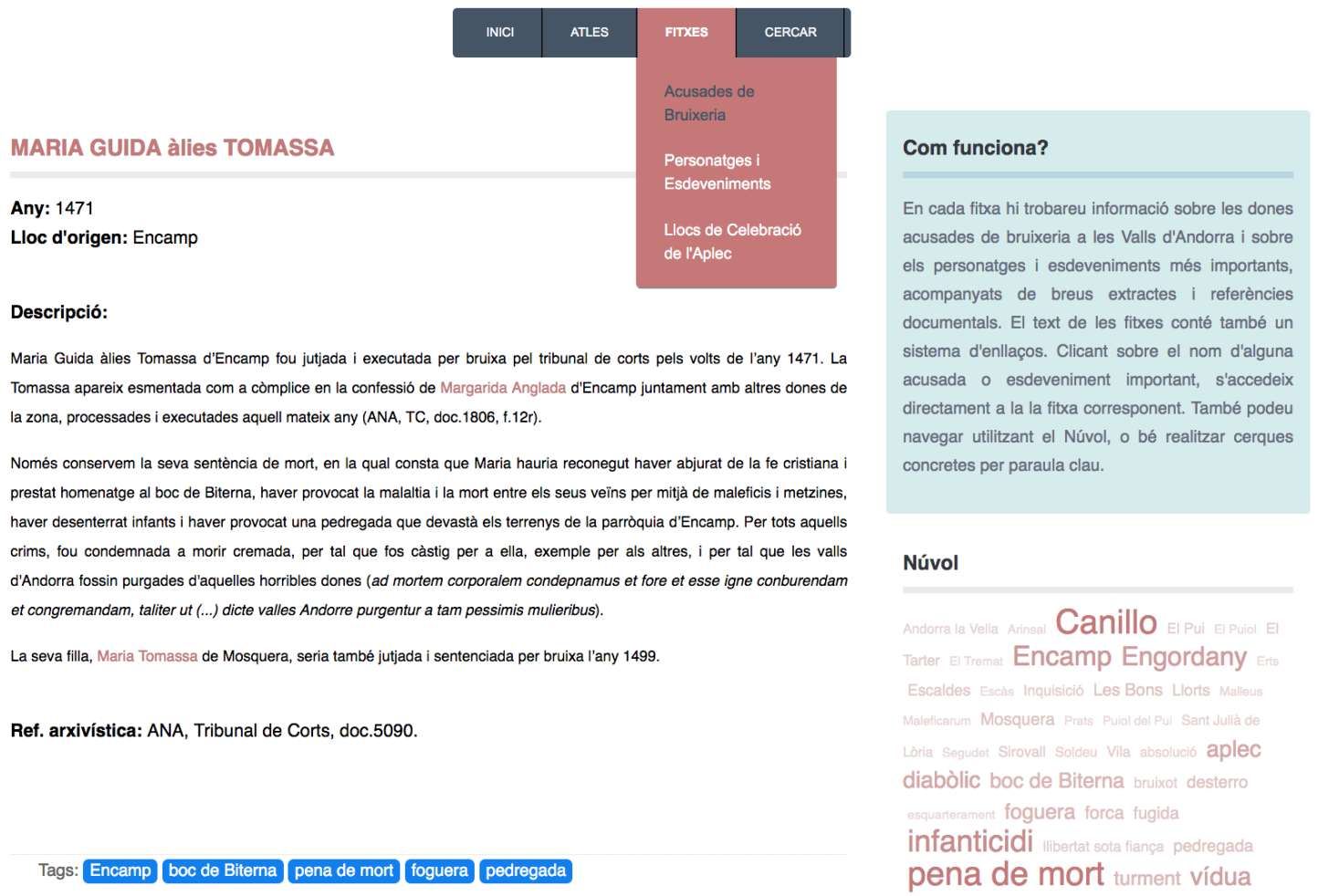

Fig. 5 Captura de pantalla d'una fitxa individual de la base de dades http://terradebruixes.cultura.ad/index.php/fitxes/acusades-de-bruixeria

\section{Primeres impressions i propostes de futur}

En el marc de l'anomenada Open Science and Responsible Research and Innovation (RRI), d'acord amb l'Horitzó 2020, un dels objectius principals de la investigació a nivell europeu és l'accés obert i la reutilització del coneixement generat a través de projectes de recerca finançats amb fons públics. En aquest sentit, es tendeix cada cop més cap a l'anomenada «FAIR data» (findable, accessible, interoperable and re-usable), això és, la voluntat que els resultats de la recerca siguin fàcilment localitzables, accessibles, interoperables i reutilitzables.

El present projecte vol ser un primer pas en aquesta direcció, tot utilitzant les eines al nostre abast per organitzar i posar a disposició el coneixement generat al llarg de la recerca a través d'una plataforma digital oberta als especialistes i al públic general. A tall d'exemple, projectes actualment en curs sobre la demografia de les Valls d'Andorra o sobre la història del dret andorrà en època moderna presenten interessants sinèrgies i punts de contacte amb la nostra investigació, fet que 
Pau Castell Granados. El projecte «terradebruixes» i els processos per bruixeria andorrans: entre

la recerca històrica i la divulgació

planteja interessants vies de col laboració i d’intercanvi en un futur immediat. Així mateix, les possibilitats que ens ofereix actualment el fet de disposar d'aquesta informació en accés obert no es limiten evidentment al camp de la recerca, sinó que reverteixen clarament en àmbits com el turisme cultural, la dinamització del territori i la posada en valor del patrimoni històric i documental andorrà.

La finalització del projecte obre també la porta a seguir ampliant i millorant en el futur la informació disponible en aquest entorn digital. D'una banda, estem col laborant actualment amb els tècnics de l'Arxiu Nacional d'Andorra per poder oferir en accés obert tota la documentació digitalitzada relativa a la persecució de la bruixeria a les valls i, en paral lel, estem treballant en la transcripció i edició paleogràfica de la totalitat dels processos per bruixeria endegats pel Tribunal de Corts andorrà durant els segles XV-XVII, que esperem vegi la llum properament en versió paper i digital. De l'altra, s'està treballant també amb el Ministeri de Cultura del Govern d'Andorra per dur a terme una traducció a l'anglès dels continguts de la web, que esperem estigui disponible al llarg de l'any 2019. L'interès que ha despertat el projecte entre alguns especialistes d'àmbit internacional ens empeny també en aquesta direcció, i converteix aquesta experiència innovadora en un possible model per a futurs projectes similars aplicables en altres territoris i àmbits de la recerca.

Finalment, creiem que les potencialitats que ens ofereixen actualment les eines digitals no ens han de fer oblidar la necessitat de la recerca de base, sense la qual no és possible generar el coneixement que posteriorment ha de ser traslladat a l'entorn digital. Les innumerables hores passades a l'arxiu, el treball paleogràfic, la recerca bibliogràfica, els intercanvis amb els especialistes i la tasca de reflexió $i$ anàlisi històrica -en definitiva, la feina dels historiadors- segueixen essent la base imprescindible $i$ necessària per seguir avançant en el camí del coneixement i la millora de la societat. 
Pau Castell Granados. El projecte «terradebruixes» i els processos per bruixeria andorrans: entre la recerca històrica i la divulgació

\section{Bibliografia}

Alcoberro, A. (2008) «Cacera de bruixes, justícia local i Inquisició a Catalunya, 1487-1643: alguns criteris metodològics», Pedralbes, 28, pp.485-504.

Alcoberro, A. (2012) «Los otros abogados de las brujas. El debate sobre la caza de brujas en Cataluña», Revista Internacional de Estudios Vascos. Cuadernos, 9, pp.92-115.

Brutails, J. A. (1904) La contume d'Andorre, Paris, Ernest Léroux Éditeur.

Castell Granados, P. (2013) Origens $i$ evolució de la cacera de bruixes a Catalunya (segles XV i XVI), Barcelona, Universitat de Barcelona. [http://www.tdx.cat/handle/10803/131462]

Castell Granados, P. (2017) «Con toda templança y moderación. El Santo Oficio ante la caza de brujas en Cataluña (siglos XVI y XVII)», dins Zamora, M. J. (ed.) Mulieres inquisitionis. La mujer frente a la Inquisición en España, Madrid, Academia de Hispanismo, pp.51-104.

Castell Granados, P. (2018) «La caza de brujas en Cataluña: un estado de la cuestión», Indice Histórico Español, 131, pp.81-114.

Galinier-Pallerola, J. F. (1990) La religion populaire en Andorre, XVe-XIXe siècles, Toulouse, Presses Universitaires du Mirail.

Pastor, R. (2004) Aquí les penjaven, Andorra la Vella, Consell General d'Andorra.

Pohle, L. M. (2008) Perquè ara-gràcies a Déu- hi ba justícia. Un estudi sobre la delinquiència a Andorra als anys 1600-1640, Barcelona, Publicacions de l'Abadia de Montserrat. 